\title{
Transport losses in finisher pigs: impact of transport distance and season of the year
}

\author{
Eva Voslarova ${ }^{1, *}$, Vladimir Vecerek ${ }^{1}$, Annamaria Passantino ${ }^{2}$, Petr Chloupek ${ }^{3}$, and Iveta Bedanova ${ }^{1}$
}

* Corresponding Author: Eva Voslarova Tel: +42-0-5-4156-2773, Fax: +42-0-5-4156-2790,

E-mail: voslarovae@vfu.cz

1 Department of Animal Protection, Welfare and Behaviour, Faculty of Veterinary Hygiene and Ecology, University of Veterinary and Pharmaceutical Sciences Brno, 61242 Brno, Czech Republic

2 Department of Veterinary Sciences, University of

Messina, 98168 Messina, Italy

${ }^{3}$ Department of Veterinary Public Health and Forensic Medicine, Faculty of Veterinary Hygiene and Ecology, University of Veterinary and Pharmaceutical Sciences Brno, 61242 Brno, Czech Republic

Submitted Apr 4, 2016; Revised Apr 27, 2016; Accepted May 2, 2016
Objective: The death of animals during transport for slaughter is a major factor indicating the level of welfare in transported animals. The aim of this study was to assess mortality related to the commercial transport of finisher pigs for slaughter in the Czech Republic. Methods: The inspectors of the State Veterinary Administration of the Czech Republic recorded the numbers of finisher pigs transported to processing plants in the Czech Republic for slaughter and the mortality in these pigs in relation to transport in the period from 2009 to 2014 .

Results: Our results show that the likelihood of death losses in transported pigs increases with increasing transport distance. The transport-related mortality ranged from $0.049 \%$ in pigs transported for distances below $50 \mathrm{~km}$ to $0.145 \%$ in pigs transported for distances exceeding $300 \mathrm{~km}$. The impact of external air temperature on the transport-related mortality found in our study clearly shows that current transport practices fail to ensure the welfare of pigs transported under other than moderate weather. Particularly cold temperatures below $-2^{\circ} \mathrm{C}$ were associated with increased death losses in winter transport.

Conclusion: Despite a decreasing trend in the mortality of finisher pigs transported for slaughter in Europe, our study suggests that current transport conditions are not efficient at ensuring the welfare of pigs during transport for longer distances and the protection of pigs against the negative impact of extreme ambient temperatures. Further research should focus on developing practical guidelines to improve the welfare of pigs in transit accordingly.

Keywords: Mortality, Swine, Transportation, Ambient Temperature, Welfare

\section{INTRODUCTION}

Most farm animals are usually moved twice during their lifetime, i.e. from the place of birth to another unit for fattening and later to the slaughterhouse. Based on salivary cortisol variation across preslaughter handling treatments, Geverink et al [1] concluded that transportation was the most stressful event for pigs prior to slaughter. Stress can result in pig fatigue, injury, poor meat quality and ultimately death [2]. Mortality records during journeys and on arrival at slaughterhouses (death on arrival, DOA) as well as rates of carcass degradation are often the only data which give information about the possible welfare status of the animals during a journey and the severity of the problems encountered as death during handling and transport is usually preceded by a period of poor welfare [3]. A review of 23 field trials conducted in the USA between 2000 and 2007 reported that of all pigs marketed, $0.25 \%$ died during transport and an additional $0.44 \%$ were non-ambulatory upon arrival at the plant [4]. An epidemiological study conducted in Eastern Canada reported that the incidence of pig mortality in transit and being non-ambulatory on arrival at the plant was $0.17 \%$ and $0.27 \%$, respectively $[5,6]$. The proportion of pigs that die during 
transport in the European Union has been estimated to range from $0.033 \%$ to $0.5 \%$ [7]. Warriss [8] found mortality rates in pigs during transport for slaughter in various European countries range from $0.1 \%$ to $1.0 \%$. Von Altrock and von Holleben [9] reported mortality in pigs resulting from stress during transport at about $0.4 \%$. Vecerek et al [10] reported the mortality rate in finisher pigs to be $0.107 \%$ in the period from 1997 to 2004. In a more recent study, a survey of 739 journeys to 37 slaughterhouses in five European Union countries was carried out, and information potentially related to the welfare and mortality of the pigs and the number of injuries were recorded. The average mortality ranged from $0 \%$ to $11 \%$, the average proportion of injured pigs ranged from $0 \%$ to $36 \%$, and these figures correlated significantly [11].

In general, losses of red meat animals during transport were reported to show a decreasing tendency over recent decades. DOA rates of pigs were about $0.7 \%$ in Dutch slaughterhouses in 1970 and decreased to $0.07 \%$ in the early 1990s. This was mainly due to progress in breeding, especially by improving the stress resistence of pig breeds such as Landrace and Pietrain which had been particularly sensitive to stress including transport [3]. Furthermore, according to Fabrega et al [12] the elimination of the halothane gene in existing breeding schemes would have a major beneficial impact from an animal welfare point of view since the removal of both $\mathrm{nn}$ and Nn genotypes would result in an eleven-fold reduction in the pre-slaughter mortality rate (from $0.22 \%$ to $0.02 \%)$. In Denmark, total mortality was reduced eight-fold during the period that the halothane gene was being removed from the pig population, from $0.12 \%$ in the early 1980 s to $0.016 \%$ in 2002 [13]. In Germany, the percentage of animals dying during or after transport clearly decreased between 1999 and 2003 [14]. The authors conclude that the tight regulations for animal transport as well as the decrease of homozygote MHS-positive pigs improved the numbers of animal losses during transport although in some areas like minimal and maximal duration of transport and transport conditions (e.g. ventilation) further changes and regulations are necessary.

The data on transport-related mortality in pigs vary widely and no recent data is available to see the current trend and impact of the latest legal regulations. Thus, the aim of this study was to assess mortality related to the commercial transport of finisher pigs for slaughter in the Czech Republic in the period from 2009 to 2014, to determine the effect of transport distance and season (external air temperature) on pig mortality and, in addition, to identify trends in the numbers of pigs dying in the process of being transported for slaughter in the monitored period.

\section{MATERIALS AND METHODS}

The inspectors of the State Veterinary Administration of the Czech Republic recorded the numbers of finisher pigs transported to processing plants in the Czech Republic for slaughter in the period from 2009 to 2014. The veterinary inspectors also recorded the mortality in these pigs in relation to transport, i.e. the number of pigs having died directly in the means of transport or having died in the processing plant after transport. The data for the whole Czech Republic was collected in database form in the Information Centre of the State Veterinary Administration. The data was analysed using a programme specially created for these purposes, which generated upon request from this database reports about the numbers of transported pigs that had died and converted them into Excel format for further statistical processing.

The impact of the transport distance on pig mortality in relation to transport to the processing plants was determined in such a way that the transport distances were divided into distances of up to $50 \mathrm{~km}, 51 \mathrm{~km}$ to $100 \mathrm{~km}, 101 \mathrm{~km}$ to $200 \mathrm{~km}$, $201 \mathrm{~km}$ to $300 \mathrm{~km}$, and over $300 \mathrm{~km}$. For these transport distances, the annual numbers of transported pigs and the annual numbers of pigs that had died were recorded in absolute numbers and mortality levels in percentages were calculated for the period from 2009 to 2014.

Seasonal impact, shown by the four seasons: spring (March, April, May), summer (June, July, August), autumn (September, October, November) and winter (December, January, February) on the mortality of finisher pigs during their transport to the processing plants was determined in such a way that for the individual seasons for the whole monitored period, the total numbers of transported pigs and the total numbers of pigs that had died were determined and the mortality rates in percentages were calculated for the period from 2009 to 2014.

In order to assess the impact of the external air temperature on the mortality of finisher pigs during their transport to the processing plants, ambient temperatures for individual journeys were determined in cooperation with the Czech Meteorological Institute. The external air temperature under which transport was carried out ranged from $-6^{\circ} \mathrm{C}$ to $21^{\circ} \mathrm{C}$ in the monitored period. For the purposes of our study, all pig journeys were divided into intervals of -6 to $-3.1^{\circ} \mathrm{C},-3^{\circ} \mathrm{C}$ to $-0.1^{\circ} \mathrm{C}, 0^{\circ} \mathrm{C}$ to $2.9^{\circ} \mathrm{C}, 3^{\circ} \mathrm{C}$ to $5.9^{\circ} \mathrm{C}, 6^{\circ} \mathrm{C}$ to $8.9^{\circ} \mathrm{C}, 9^{\circ} \mathrm{C}$ to $11.9^{\circ} \mathrm{C}, 12^{\circ} \mathrm{C}$ to $14.9^{\circ} \mathrm{C}, 15^{\circ} \mathrm{C}$ to $17.9^{\circ} \mathrm{C}$ and $18^{\circ} \mathrm{C}$ to $21^{\circ} \mathrm{C}$. For these intervals, the numbers of transported pigs and the numbers of pigs that had died were recorded in absolute numbers and the mortality levels in percentages were calculated for the period from 2009 to 2014.

Data were analysed using the statistical package Unistat v. 6.5. (Unistat Ltd., London, England). Statistical comparisons between the frequencies of the categorical variables of interest were performed with the Chi-square test (with Yates correction) within the $2 \times 2$ Contingency table procedure. When the 
Table 1. The numbers of finisher pigs transported to slaughterhouses and numbers of pigs dying as a result of their transport for monitored distances

\begin{tabular}{|c|c|c|c|c|c|c|c|}
\hline \multicolumn{2}{|c|}{ Distance (km) } & 2009 & 2010 & 2011 & 2012 & 2013 & 2014 \\
\hline Distance & & \multicolumn{6}{|c|}{ Number of pigs } \\
\hline \multirow[t]{2}{*}{$<50$} & Transported & $1,630,148$ & $1,607,134$ & $1,447,080$ & $1,265,765$ & $1,225,998$ & $1,104,573$ \\
\hline & Dead & 806 & 859 & 807 & 607 & 622 & 360 \\
\hline \multirow[t]{2}{*}{$50-100$} & Transported & 890,239 & 826,696 & 731,982 & 591,224 & 632,811 & 731,174 \\
\hline & Dead & 813 & 906 & 612 & 410 & 385 & 536 \\
\hline \multirow[t]{2}{*}{$101-200$} & Transported & 342,103 & 394,923 & 482,629 & 527,032 & 508,005 & 571,176 \\
\hline & Dead & 507 & 475 & 442 & 401 & 403 & 331 \\
\hline \multirow[t]{2}{*}{$201-300$} & Transported & 134,747 & 133,970 & 139,846 & 94,100 & 133,895 & 163,804 \\
\hline & Dead & 190 & 139 & 109 & 103 & 128 & 191 \\
\hline \multirow[t]{2}{*}{$300<$} & Transported & 23,096 & 19,343 & 20,855 & 53,038 & 22,109 & 21,235 \\
\hline & Dead & 31 & 41 & 27 & 67 & 26 & 39 \\
\hline
\end{tabular}

frequencies in the contingency table were lower than 5 , a Fisher exact test was used instead of Chi-square test [15]. Data concerning transport-related mortality rates in finisher pigs were compared between individual years and transport distances monitored, and also differences in mortality rates among seasons of the year were tested for the whole period from 2009 to 2014. Data concerning mean mortality rates in pigs as affected by the ambient temperature for the entire period monitored in the study were compared by a one-way analysis of variance and subsequently by a Tukey-honestly significant difference test [15] as a post hoc test for pairwise comparisons. To assess the trend in mortality rates during the monitored years, a Spearman rank correlation coefficient [15] including its significance was calculated. A p value of 0.05 in tests was considered significant.

\section{RESULTS}

The numbers of finisher pigs transported for slaughter in the Czech Republic and the numbers of pigs dying as a result of their transport for monitored distances are given in Table 1. The overall numbers of pigs transported for slaughter in the

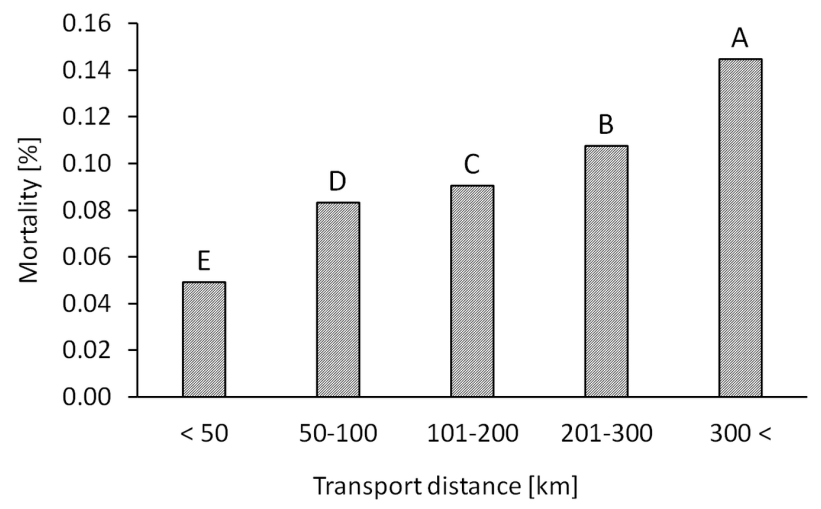

Figure 1. Transport-related mortality of finisher pigs as affected by transport distance. ${ }^{A-E}$ Mortality in columns with different superscripts differ significantly $(p<0.001)$.
Czech Republic were decreasing in the monitored period. The transport-related mortality of finisher pigs for transport distances monitored in our study is presented in Figure 1. A statistically highly significant $(\mathrm{p}<0.001)$ impact of the transport distance on the transport-related mortality in pigs was found. The lowest mortality $(0.049 \%)$ was found in pigs transported for distances below $50 \mathrm{~km}$, the longer distances were associated with significantly $(\mathrm{p}<0.001)$ increasing death losses with the highest losses $(0.145 \%)$ recorded for distances exceeding $300 \mathrm{~km}$.

The transport-related mortality of finisher pigs as affected by the season of the year is shown in Figure 2. The highest mortality $(0.075 \%)$ was associated with transport carried out in the winter months. Significantly $(\mathrm{p}<0.01)$ lower death losses were associated with transportcarried out in the summer months $(0.070 \%)$. The lowest death losses were found in pigs transported for slaughter in the spring $(0.066 \%)$ and autumn $(0.066 \%)$ months; with no significant difference between these two seasons.

The impact of the ambient temperature on the transportrelated mortality of finisher pigs is shown in Figure 3. Transport carried out under the ambient temperatures $-6^{\circ} \mathrm{C}$

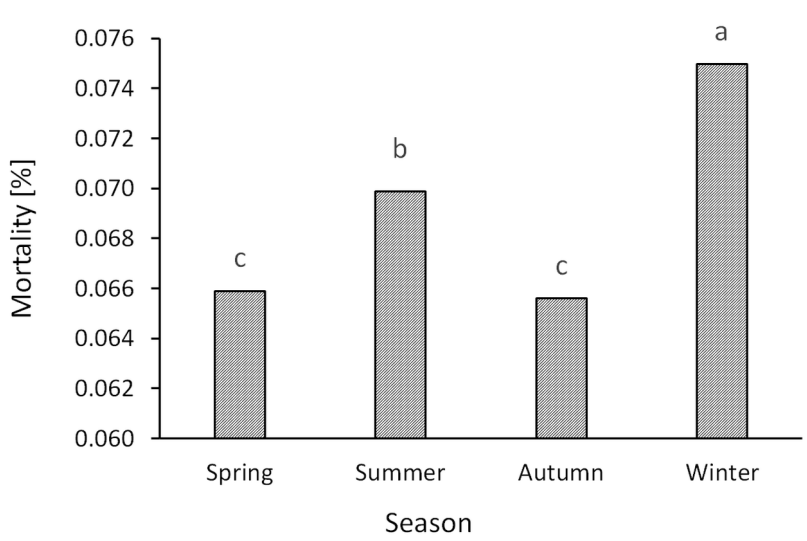

Figure 2. Transport-related mortality of finisher pigs as affected by the season of the year. ${ }^{a, b, c}$ Mortality in columns with different superscripts differ significantly $(p<0.05)$. 


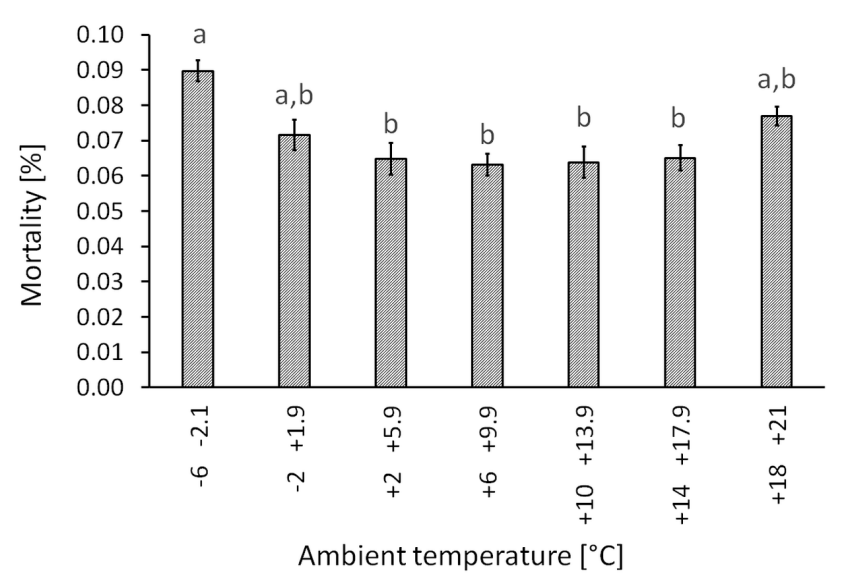

Figure 3. Transport-related mortality of finisher pigs as affected by the ambient temperature (mean \pm standard error of the mean). ${ }^{a, b}$ Means with different superscripts differ significantly $(p<0.05)$.

to $-2.1^{\circ} \mathrm{C}$ (the lowest temperatures observed in our study) and temperatures $18^{\circ} \mathrm{C}$ to $21^{\circ} \mathrm{C}$ (the highest temperatures observed in our study) were associated with the highest death losses of pigs. However, a significant difference $(\mathrm{p}<0.001)$ was found only between the mortality rates related to transport carried out under the ambient temperatures $-6^{\circ} \mathrm{C}$ to $-2.1^{\circ} \mathrm{C}$ and mortality rates related to transport carried out under the ambient temperatures $2^{\circ} \mathrm{C}$ to $17.9^{\circ} \mathrm{C}$. The mortality related to transport of finisher pigs carried out under a temperature range from $-2^{\circ} \mathrm{C}$ to $21^{\circ} \mathrm{C}$ did not significantly differ.

The trend in the transport-related mortality in finisher pigs in the period from 2009 to 2014 is shown in Figure 4. The highest mortality was found in $2010(0.081 \%)$ whereas the lowest mortality in pigs transported for slaughter was in 2014 $(0.056 \%)$. A significant negative correlation $(\mathrm{r}=-0.9429, \mathrm{p}=$ 0.005 ) was found between mortality rates and monitored years in finisher pigs indicating a decreasing tendency in pig losses in the monitored period.

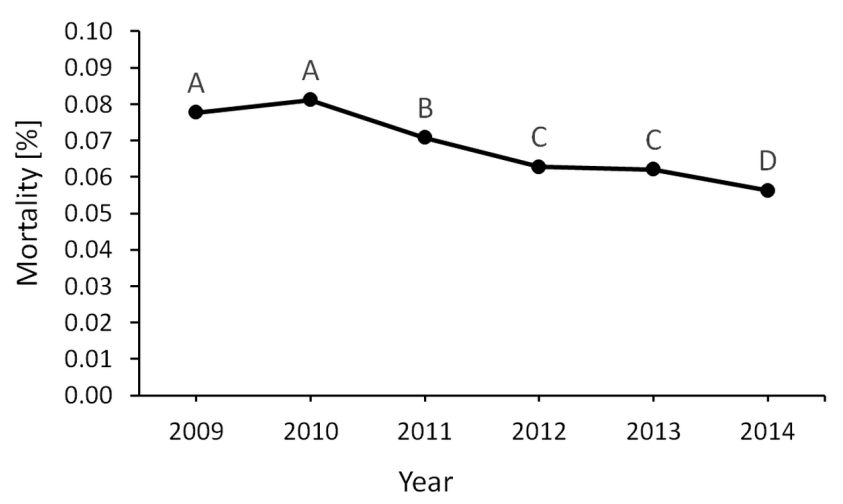

Figure 4. Trends in the transport-related mortality in finisher pigs in the period from 2009 to $2014 .{ }^{A-D}$ Mortality in columns with different superscripts differ significantly $(p<0.01)$.

\section{DISCUSSION}

The average mortality of pigs recorded in the past in several European Union countries ranged from $0 \%$ to $11 \%$ [11], records from the USA and Canada showed pig mortality in transit below 1\% [4-6]. Over recent decades, the losses of pigs during transport have been reported to show a decreasing tendency in Europe [3,12-14]. In the Czech Republic, transport-related mortality in finisher pigs decreased by one third in the period from 2009 to 2014 in comparison to the earlier studies investigating mortalities among pigs transported for slaughter in the Czech Republic in the period from 1997 to $2006[10,16]$. Furthermore, the results of the present study show a significant negative correlation between mortality rates and monitored years in finisher pigs indicating a continuing decreasing tendency in pig losses in the monitored period. However, transport-related mortality in pigs still represents a substantial loss of the total number of transported pigs. Furthermore, Averos et al [11] found that mortality correlates with the proportion of injured pigs in transit. If their injuries are especially located on the most valuable cuts such as hams, loins and shoulders, these can increase the economic loss [17]. Facing the decline in pig herds attributed mainly to low profitability it is even more important to also avoid an economic loss as a consequence of death and reduced carcass value. Our results show that the likelihood of death losses in transported pigs increases with increasing transport distance. The transport-related mortality ranged from $0.049 \%$ in pigs transported for distances below $50 \mathrm{~km}$ to $0.145 \%$ in pigs transported for distances exceeding $300 \mathrm{~km}$. Despite less than half the pigs being transported for distances over $50 \mathrm{~km}$, such transports accounted for $64.29 \%$ death losses. Transport mortality has been also reported by Gade et al [13] to increase with increasing transport distance in Danish pig transport. Similarly, Warriss [8] found higher mortality after longer journeys. In contrast, Dewey et al [6] reported in-transit losses of finisher pigs marketed in Canada to increase sharply between distances travelled of 590 to $720 \mathrm{~km}$ and decreased at distances greater than $980 \mathrm{~km}$. Similarly, Perez et al [18] concluded that under normal Spanish commercial conditions, pigs subjected to short transport showed a more intense stress response and poorer meat quality than pigs subjected to moderately long transport when they were immediately slaughtered on arrival at the slaughterhouse. Longer transport might have allowed the animals to adapt to transport conditions and then could act as a resting period similar to a lairage time. Haley et al [19] found that for each $50 \mathrm{~km}$ increase in distance, DOA can be expected to decrease 0.81 times and reported a decreased risk of in-transit death losses with distances over $134 \mathrm{~km}$. However, such a positive effect of prolonged journey time was not seen in our study. Conversely, a linear relationship between journey length and transport 
stress resulting to increased death losses with increasing transport distance was found within the range of distances for which are pigs transported in the Czech Republic. Same negative impact of increasing transport distance on increasing death losses associated with transport has been reported in broiler chickens [20].

The impact of external air temperature on the transport-related mortality found in our study clearly shows that current transport practices fail to ensure the welfare of pigs transported under other than moderate weather. Particularly cold temperatures below $-2^{\circ} \mathrm{C}$ were associated with increased death losses in winter transport. Negative consequencies of pig transport in cold weather were also reported by other authors. Ritter et al [21] found a higher incidence of total nonambulatory pigs in the winter than in the spring and summer. Correa et al [22] found higher heart rates during transport, at unloading and in lairage in winter than in summer. They also reported increased occurence of bruises in pigs transported in winter. Similarly, dalla Costa et al [23] observed a higher number of bruises on the body at unloading and slaughter and a higher number of bruises on the carcass in winter. They concluded that the higher number of bruises recorded in winter had resulted from pigs huddling together to better cope with cold temperatures. This huddling behavior reduces the space allowance leading pigs to fight or climb over the backs of other pen mates to seek a place to rest. This behaviour may also be the cause of the increased transportrelated mortality in winter found in our study.

In-transit mortality has been also reported to increase with increasing temperature $[13,24,25]$, particularly beyond ambient temperatures of $16^{\circ} \mathrm{C}$ to $17^{\circ} \mathrm{C}[25,26]$. As pigs do not sweat, have relatively small lungs and thick subcutaneous fat, they are limited in their capacity to maintain core body temperature in hot environments and are prone to heat stress. According to Averos et al [11], the risk of mortality increases with rising average temperature. In journeys with fasted pigs that did not have any recorded injury, average temperature was more important than the duration of the journey. Warriss [8] found increased mortality in pigs transported at ambient temperatures higher than $10^{\circ} \mathrm{C}$. Warriss and Brown [26] reported more pigs dying in transit in months when the weather was hotter. The relationship to temperature was curvilinear; above about $15^{\circ} \mathrm{C}$ to $17^{\circ} \mathrm{C}$ the detrimental effect of high temperatures was far more serious. In our study, transport-related mortality in pigs transported at ambient temperatures ranging from $18^{\circ} \mathrm{C}$ to $21^{\circ} \mathrm{C}$ (the highest temperatures observed in our study) statistically did not differ from the mortality of pigs transported at the coldest temperatures observed in the monitored period, i.e. the temperatures associated with the highest death losses found in our study. However, the mortality related to hot weather was slightly lower and did not statistically differ from mortality rates in pigs transported at any other temperature interval observed in our study. This finding also differs from the earlier study by Vecerek et al [10] investigating mortality rates among pigs transported for slaughter in the Czech Republic in the period from 1997 to 2006. They reported the highest losses in the summer months when the ambient temperature was highest (higher than $15^{\circ} \mathrm{C}$ ). However, such a development is in accordance with the study by Werner et al [14]. They reported a reduction in pig mortality in the hot summer months (a season previously with high losses over the years) in Germany and attributed this reduction to a decrease in death losses related to the transport of pigs in general between the years 1999 and 2003. This might be due to the better management of transport during hot days in recent years since the risks of heat stress and measures to be taken to reduce transport-related mortality during hot summer months have been well described. However, our results suggest that protection against cold temperatures in winter transport is not yet effective. According to Gade et al [13], particular efforts to reduce transport mortality should be made if weather forecasts predict dangerous combinations of temperature and humidity.

Furthermore, Correa et al [22] found that not only the season but also the type of vehicle and animal location in the trailer affect the welfare of pigs during transport with clear consequences such as skin bruises and pork quality variation. Since variation in thermal conditions exists between compartments within each trailer, Brown et al [27] suggested that transport conditions may be improved by increasing ventilation to the lower-front compartments and in upper-rear compartments in summer, or by a combination of insulation and ventilation in winter. Fox et al [28] found that sprinkling pigs in a stationary vehicle when ambient temperature external to the trailer exceeds $23^{\circ} \mathrm{C}$ has the potential to prevent increases in body temperature during short duration transport without detrimental effects on ammonia levels or behaviour during unloading.

In conclusion, the death of animals during transport for slaughter is a major factor indicating the level of welfare in transported animals. Despite a decreasing tendency in the mortality of finisher pigs transported for slaughter in Europe, our study suggests that current transport conditions are not effective at ensuring the welfare of pigs during transport for longer distances and the protection of pigs against the negative impact of extreme ambient temperatures. Further research should focus on developing practical guidelines to improve the welfare of the pigs in transit accordingly.

\section{CONFLICT OF INTEREST}

We certify that there is no conflict of interest with any financial organization regarding the material discussed in the manuscript. 


\section{REFERENCES}

1.Geverink NA, Kappers A, van de Burgwal JA, et al. Effects of regular moving and handling on the behavioral and physiological responses of pigs to preslaughter treatment and consequences for subsequent meat quality. J Anim Sci 1998;76:2080-5.

2.Bench C, Schaefer AL, Faucitano L. The welfare of pigs during transport. In: Faucitano L, Schaefer AL, editors. The welfare of pigs - from birth to slaughter. Wageningen: Wageningen Academic Publishers; 2008. p. 161-95.

3.Smulders FJM, Algers B. Welfare of production animals: assessment and management of risks. Wageningen: Wageningen Academic Publishers; 2009.

4.Ritter MJ, Ellis M, Berry NL, et al. Review: Transport losses in market weight pigs: I. A review of definitions, incidence, and economic impact. Prof Anim Sci 2009;25:404-14.

5.Sunstrum J, Dewey C, Haley C. Clinical signs of stress in finisher pigs transported to market in the summer. Swine News 2007;30: $1-2$.

6.Dewey CE, Haley C, Widowski T, Poljak Z, Friendship RM. Factors associated with in-transit losses of fattening pigs. Anim Welf 2009; 18:355-61

7.Warriss PD. Guidelines for the handling of pig ante-mortem: interim conclusion from EC-AIR3-project CT920262. Landbauforsch Volk 1996;S166:217-25.

8. Warriss PD. The welfare of slaughter pigs during transport. Anim Welf 1998;7:365-81.

9.von Altrock A, von Holleben K. Sudden deaths in fattening herds on taking blood samples - Experiences from the practice. Berl Munch Tierarztl Wochenschr 1999;112:86-90.

10. Vecerek V, Malena M, Malena M Jr, Voslarova E, Chloupek P. The impact of the transport distance and season on losses of fattened pigs during transport to the slaughterhouse in the Czech Republic in the period from 1997 to 2004. Vet Med-Czech 2006;51:21-8.

11. Averos X, Knowles TG, Brown SN, Warriss PD, Gosalvez LF. Factors affecting the mortality of pigs being transported to slaughter. Vet Rec 2008;163:386-90.

12. Fabrega E, Diestre A, Carrion D, Font J, Manteca X. Effect of the halothane gene on pre-slaughter mortality in two Spanish commercial pig abattoirs. Anim Welf 2002;11:449-52.

13. Gade PB, Christensen L, Baltzer M, Petersen JV. Causes of preslaughter mortality in Danish slaughter pigs with special emphasis on transport. Anim Welf 2007;16:459-70.

14. Werner C, Reiners K, Wicke M. Mortality rates during transport of slaughter pigs. Fleischwirtschaft 2005;85:133-6.
15. Zar JH. Biostatistical Analysis. 4th ed. Upper Saddle River, NJ: Prentice Hall; 1999.

16. Malena M, Voslarova E, Kozak A, et al. Comparison of mortality rates in different categories of pigs and cattle during transport for slaughter. Acta Vet Brno 2007;76:109-16.

17. Arduini A, Redaelli V, Luzi F, et al. Effect of transport distance and season on some defects of fresh hams destined for DPO production. Animals 2014;4:524-34.

18. Perez MP, Palacio J, Santolaria MP, et al. Effect of transport time on welfare and meat quality in pigs. Meat Sci 2002;61:425-33.

19. Haley C, Dewey CE, Widowski T, Poljak Z, Friendship R. Factors associated with in-transit losses of market hogs in Ontario in 2001. Can J Vet Res 2008;72:377-84.

20. Vecerek V, Voslarova E, Conte F, Vecerkova L, Bedanova I. Negative trends in transport-related mortality rates in broiler chickens. AsianAustralas J Anim Sci 2016;29:1796-804.

21. Ritter MJ, Ellis M, Bowman R, et al. Effects of season and distance moved during loading on transport losses of market-weight pigs in two commercially available types of trailer. J Anim Sci 2008; $86: 3137-45$

22. Correa JA, Gonyou HW, Torrey S, et al. Welfare and carcass and meat quality of pigs being transported for two hours using two vehicle types during two seasons of the year. Can J Anim Sci 2013; 93:43-55.

23. dalla Costa OA, Faucitano L, Coldebella A, et al. Effects of the season of the year, truck type and location on truck on skin bruises and meat quality in pigs. Livest Sci 2007;107:29-36.

24. Sutherland MA, McDonald A, McGlone JJ. Effects of variations in the environment, length of journey and type of trailer on the mortality and morbidity of pigs being transported to slaughter. Vet Rec 2009;165:13-8.

25. Haley C, Dewey CE, Widowski T, Friendship R. Relationship between estimated finishing-pig space allowance and in-transit loss in a retrospective survey of 3 packing plants in Ontario in 2003. Can J Vet Res 2010;74:178-84.

26. Warriss PD, Brown SN. A survey of mortality in slaughter pigs during transport and lairage. Vet Rec 1994;134:513-15.

27. Brown JA, Samarakone TS, Crowe T, et al. Temperature and humidity conditions in trucks transporting pigs in two seasons in Eastern and Western Canada. Trans ASABE 2011;54:2311-8.

28. Fox J, Widowski T, Torrey $S$, et al. Water sprinkling market pigs in a stationary trailer: 1 . Effects on pig behaviour, gastrointestinal tract temperature and trailer micro-climate. Livest Sci 2014;160: 113-23. 